Full length article

\title{
Surface texturing of steel by femtosecond laser and accompanying structure/ phase transformations
}

\author{
M.V. Zhidkov", , T.N. Vershinina, ${ }^{\mathrm{a}, \mathrm{f}}$, O.A. Golosova ${ }^{\mathrm{b}}$, S.I. Kudryashov ${ }^{\mathrm{c}, \mathrm{d}, \mathrm{e}}$, A.A. Ionin ${ }^{\mathrm{c}}$ \\ ${ }^{a}$ Belgorod State National Research University, Pobedy Str., 85, Belgorod 308015, Russia \\ ${ }^{\mathrm{b}}$ Merzhanov Institute of Structural Macrokinetics and Materials Science, Russian Academy of Sciences, Academician Osipyan Str., 8, Chernogolovka 142432, Russia \\ ${ }^{\mathrm{c}}$ Lebedev Physical Institute, Russian Academy of Sciences, Leninskiy Pr., 53, Moscow 119991, Russia \\ ${ }^{\mathrm{d}}$ ITMO University, 49, Kronverksky Pr., 197101 St. Petersburg, Russia \\ e National Research Nuclear University MEPhI (Moscow Engineering Physics Institute), 31, Kashirskoe Shosse, 115409 Moscow, Russia \\ ${ }^{\mathrm{f}}$ Joint Institute for Nuclear Research, Joliot-Curie Str., 6, Dubna, Moscow Region 141980, Russia
}

\section{H I G H L I G H T S}

- Surface textures of austenite steel were produced by femtosecond laser.

- One-dimensional nanograting and microrelief of various roughness have been received.

- Ferrite $(\alpha-\mathrm{Fe})$ in the near-surface layers was formed in spallation regime.

- Phases $\alpha-\mathrm{Fe}, \mathrm{Fe}_{3} \mathrm{O}_{4}, \gamma-\mathrm{Fe}_{2} \mathrm{O}_{3}$ in the near-surface layers were formed in the phase explosion regimes.

- Heat-affected zone was observed in the high-fluence mode for phase explosion regime.

\section{A R T I C L E I N F O}

\section{Keywords:}

Stainless steel

Femtosecond laser irradiation

Laser ablation

Phase transformations

\begin{abstract}
A B S T R A C T
Topography, structure, and phase composition of surface layers of AISI 321 stainless steel textured by 1030-nm 320 -fs-laser pulses were studied by scanning electron microscopy and X-ray diffraction analysis. Variation in single-pulse fluence and the number of pulses was found to change the laser-produced surface texture from onedimensional quasi-periodic nanograting to microrelief of various roughness. It was shown that the nanograting formed in the spallation regime contained austenite, just as a non-irradiated steel surface, and ferrite. The redeposited oxide layers on the grating surface produced in the phase explosion regime with a thickness increasing versus single-pulse fluence were found to consist of austenite, ferrite, and $\mathrm{Fe}_{3} \mathrm{O}_{4}$. In case of high-fluence mode, the two-layer microporous oxide coating, consisting of $\mathrm{Fe}_{3} \mathrm{O}_{4}$ and $\mathrm{Fe}_{2} \mathrm{O}_{3}$ in addition to conventional phases, was detected. SEM studies showed that the submicrocrystalline structure of nano- and microsized ridges was preserved, except for the high-fluence mode.
\end{abstract}

\section{Introduction}

Laser-induced textures-from a subwavelength- [1-3] or wavelength-scale $[4,5]$ periodic relief to a developed quasi-periodic microrelief of varied roughness [6] — can be formed on the material surface under the action of femtosecond (fs) laser pulses. The relief produced by fs laser ablation was found to show unique properties, such as superhydrophilicity [7] or superhydrophobicity [8-10], as well as almost $100 \%$ optical absorbance $[11,12]$. Main features of relief formation on stainless steel surface, which changes its wetting properties, were extensively studied in $[1,8,9,13-20]$. Peening of stainless steel due to shock loading induced by fs laser ablation was investigated in [21,22]. However, structural and phase transformations in near-surface layers of such stainless austenitic steel exposed by fs-laser pulses have not been studied sufficiently. In this work, we aimed to fill this gap for the case of AISI 321 austenitic stainless steel.

\section{Experimental}

In our experiments, submicrocrystalline AISI 321 stainless steel (Fe-0.12C-18Cr-10Ni-0.5Ti) was used. This material was prepared in the form of rectangular slabs, whose surfaces were mechanically

\footnotetext{
* Corresponding author.

E-mail addresses: zhidkov@bsu.edu.ru (M.V. Zhidkov), vershinina@bsu.edu.ru (T.N. Vershinina), golosova@ism.ac.ru (O.A. Golosova), sikudr@sci.lebedev.ru (S.I. Kudryashov), aion@sci.lebedev.ru (A.A. Ionin).
} 
Table 1

Irradiation modes 1-4 used in experiment.

\begin{tabular}{llllll}
\hline & $\sigma, \mu \mathrm{m}$ & $E, \mu \mathrm{J}$ & $f, \mathrm{kHz}$ & $F_{0}, \mathrm{~J} / \mathrm{cm}^{2}$ & $N$ \\
\hline $\mathbf{1}$ & \multirow{2}{*}{35} & 2 & 1 & 0.21 & 12 \\
$\mathbf{3}$ & & 2 & 250 & 0.21 & 3800 \\
$\mathbf{4}$ & \multirow{2}{*}{15} & 6 & 250 & 0.63 & 3800 \\
& & 6 & 250 & 3.4 & 600 \\
\hline
\end{tabular}

polished, using a rotary polishing machine LaboPol-5 (Struers).

The samples were arranged on a PC-controlled three-dimensional motorized translation stage and scanned in a number of parallel lines by 1030 -nm 320-fs Yb-fiber pulses, coming at a rate $f=250 \mathrm{kHz}$ with the maximal energy of $10 \mu \mathrm{J}$ in the $\mathrm{TEM}_{00}$ mode. Fs-laser radiation parameters-laser spot (1/e diameter) $\sigma$, pulse energy $E$, impulse frequency $f$, single-pulse fluence $F_{0}$, and number of pulses $N$ - are given in Table 1.

The structure of the laser-affected surface was studied by a Zeiss Ultra plus scanning electron microscope (SEM) and a FEI Quanta 600 SEM, equipped by an energy dispersive spectrometer (EDX) (resolution $-0.2-0.25 \%$ ). The surface topography was characterized by a Ntegra Aura atomic force microscope. X-ray diffraction (XRD) analysis was performed, using an ARL X'TRA X-ray diffractometer with $\mathrm{CuK}_{\alpha}$ radiation in the Bragg-Brentano focusing and sliding regimes.

\section{Results and discussion}

Surface topography. Ablation threshold fluence $\left(F_{\text {th }}\right)$ for surface of metallic materials irradiated by ultrashort laser pulses is a key parameter that defines the features of resulting relief [23]. In case of fs-laser pulses, two possible ablation mechanisms-spallation and phase explosion (laser explosive boiling [24])—have been suggested. For a single fs pulse and stainless steel [19], the thresholds for spallation ablation $F_{\text {spal }}$ and ablation of phase explosion $F_{\text {phe }}$ were found to have the values of $\approx 0.29 \mathrm{~J} / \mathrm{cm}^{2}$ and $0.55 \mathrm{~J} / \mathrm{cm}^{2}$, respectively. The singlepulse fluences $F_{0}$ presented in Table 1 for modes $\mathbf{1}$ and $\mathbf{2}$ are smaller than $F_{\text {spal, }}$, whereas for modes $\mathbf{3}$ and $\mathbf{4}$ are seen to exceed $F_{\text {phe }}$.

It is also known that laser irradiation by a train of $N$ pulses can reduce the ablation threshold due to the so-called cumulative effect, i.e. decrease $F_{\text {th }}$ with increasing $N$. For metals, it has been proposed that such effect is due to the accumulation of plastic deformation, resulting from laser induced thermal stress fields [25]. Accumulation behaviour on ablation threshold was demonstrated for ns [26], ps [26] and fs [27] pulse duration. The expression for $F_{\text {th }}(N)$ can be written in the form [25]:

$\mathrm{F}_{\mathrm{th}}(\mathrm{N})=\mathrm{F}_{\mathrm{th}}(1) \mathrm{N}^{\mathrm{S}--1}$

where $S$ is the cumulative parameter equal to 0.86 for stainless steel [24].

For mode $1\left(F_{0} \approx 0.21 \mathrm{~J} / \mathrm{cm}^{2}\right.$ and $N=12$, see Table 1$)$, the laseraffected steel surface represents a one-dimensional quasi-periodic structure (nanograting), consisting of ridges with a width of about 30-60 $\mathrm{nm}$ and spherical nanoparticles with their size between 15 and $160 \mathrm{~nm}$ (Fig. 1a-1c). The ridges are parallel to the direction of laser polarization. The period of the subwavelength structure is about $300 \mathrm{~nm}$. As a rule, such a nanograting is formed at relatively low fluences ( $\leq F_{\text {spal }}$ ). In this mode, $F_{\text {spal }}$ at $N=12$, as derived from Eq. (1), is equal to the $F_{0}$ value used in the experiment. Our relief is similar to that simulated in [28] in terms of spallation ablation mechanism applied to Cr single crystals.

At $N=3800$ (mode 2), $F_{\text {phe }}$ calculated using Eq. (1), is about $0.17 \mathrm{~J} / \mathrm{cm}^{2}$. Thus, the phase explosion can occur for $N \geq 3000$. In this mode, the microgratings are oriented along the direction of beam scan (Fig. 1d, 1f). The ridge heights are about $5 \mu \mathrm{m}$. On the microridge surface, there are submicron particles and their agglomerates (Fig. 1e) that are probably oxidized ablation products. The oxygen content in the

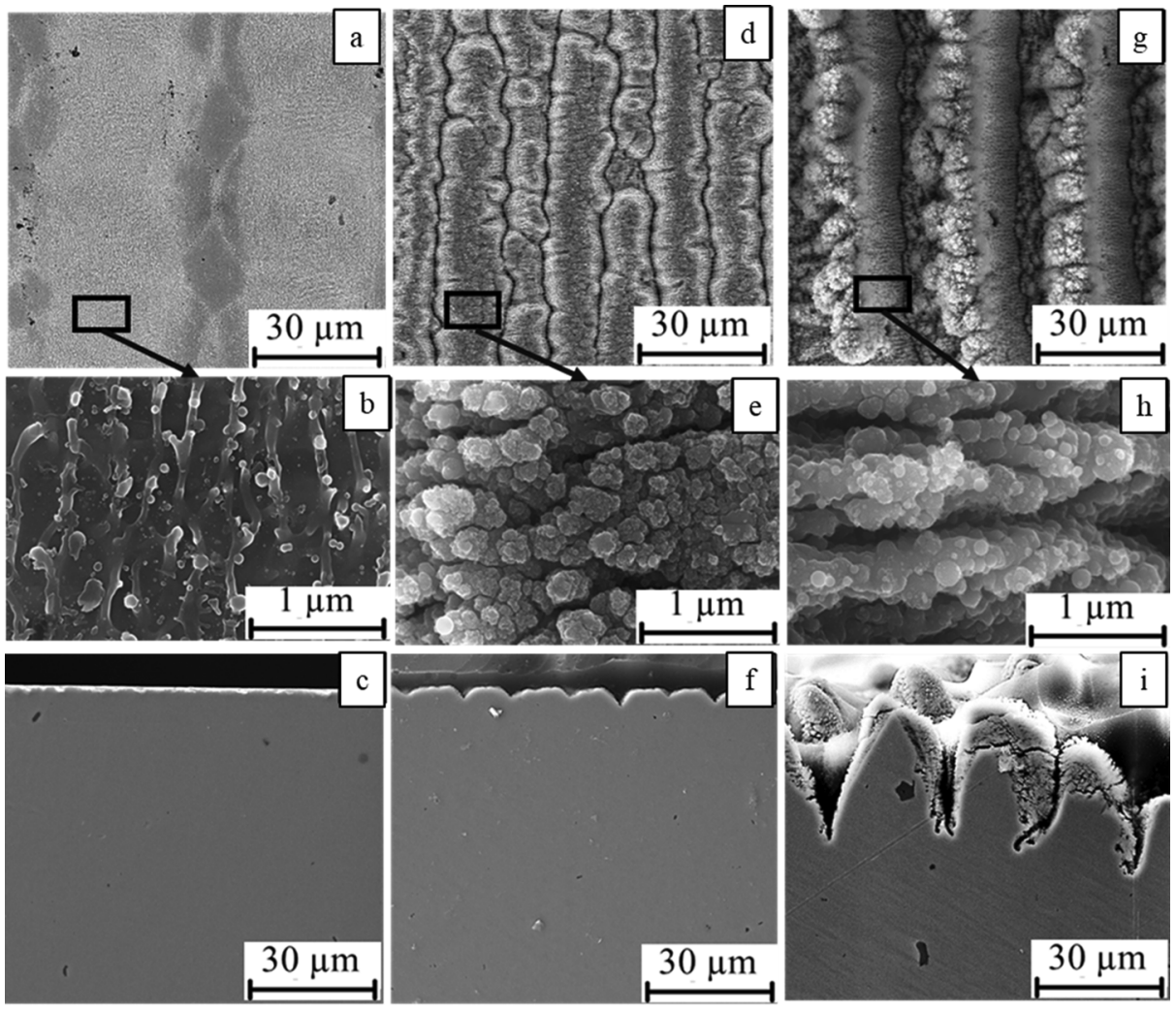

Fig. 1. (a, b, d, e, g, h) Top-view topography of surface and (c, f, i) cross sectional SEM view of samples of AISI 321 steel affected by fs laser pulses: (a-c) $F_{0}=0.21 \mathrm{~J} /$ $\mathrm{cm}^{2}$ and $N=12$; (d-f) $F_{0}=0.21 \mathrm{~J} / \mathrm{cm}^{2}$ and $N=3800$; and $(\mathrm{g}-\mathrm{i}) F_{0}=0.63 \mathrm{~J} / \mathrm{cm}^{2}$ and $N=3800$. 


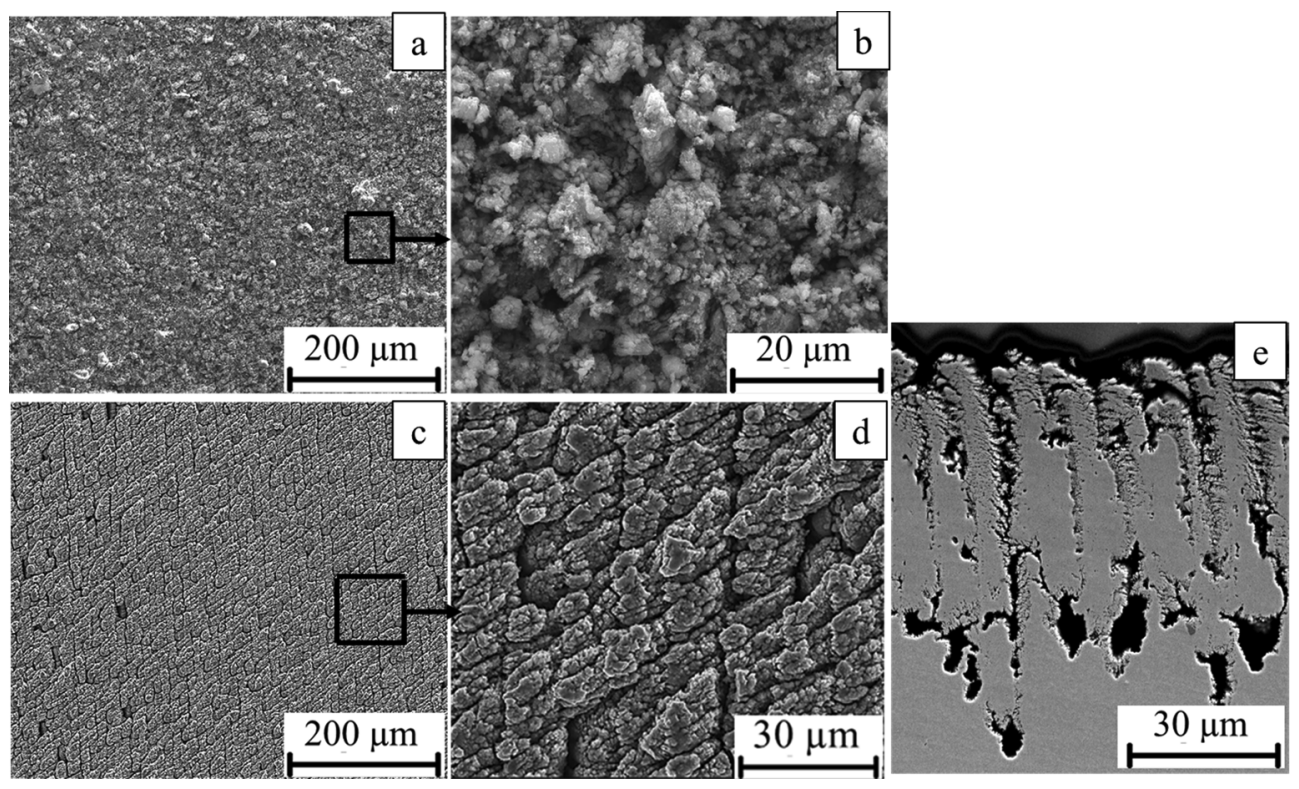

Fig. 2. Fs-laser affected topography of surface of AISI 321 steel pulses in mode 4: (a, b) surface upper layer; (c, d) subsurface (underlying) layer; and (e) cross section of subsurface layer.

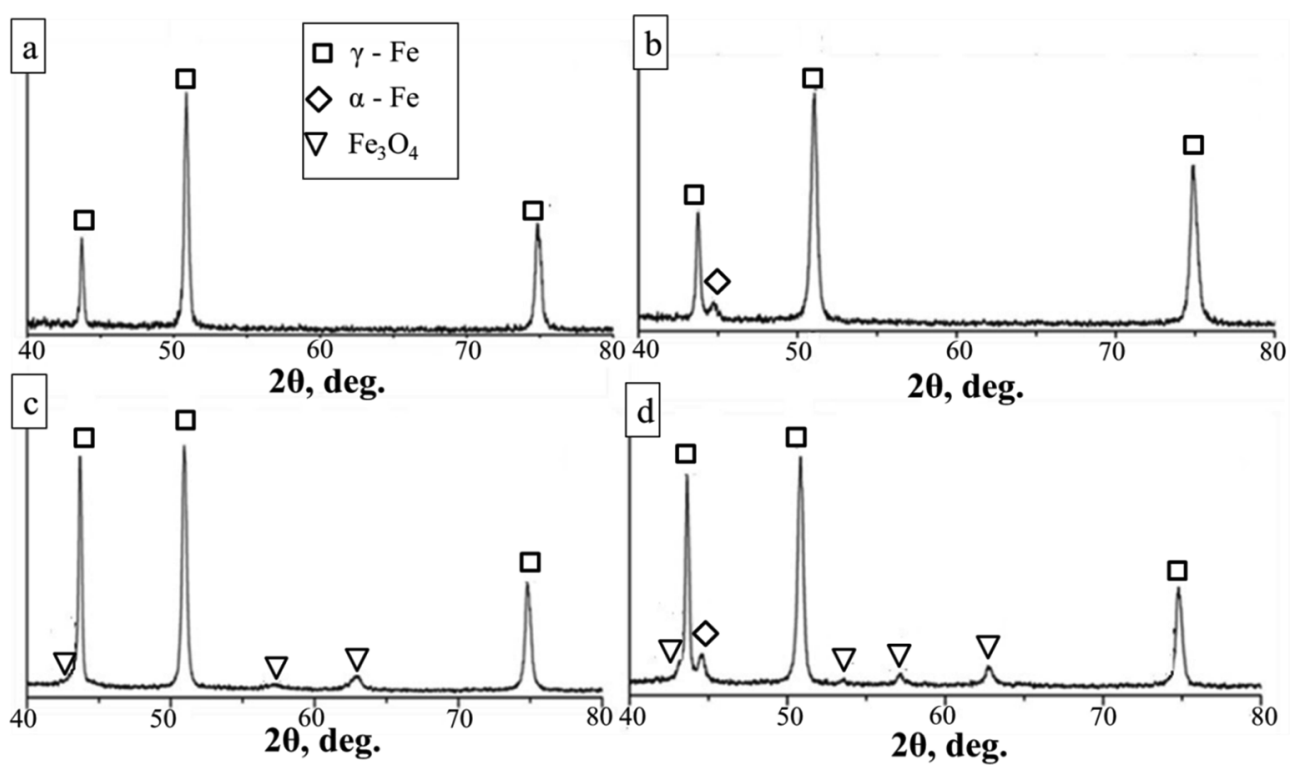

Fig 3. XRD patterns of steel (a) in the initial state and (b-d) after fs-laser radiation: (b) $F_{0}=0.21 \mathrm{~J} / \mathrm{cm}^{2}, N=12 ;\left(\right.$ b) $F_{0}=0.21 \mathrm{~J} / \mathrm{cm}^{2}, N=3800$; and (c) $F_{0}=0.63 \mathrm{~J} / \mathrm{cm}^{2}, N=3800$.

surface layer is $~ 15-20 \mathrm{wt} \%$.

The $25-\mu \mathrm{m}$ wide and $20-\mu \mathrm{m}$ tall microridges are formed on the steel surface at $F_{0} \approx 0.63 \mathrm{~J} / \mathrm{cm}^{2}$ and $N=3800$ (mode 3 , cf. Table 1 and Fig. 1g-1i). Unlike mode 2, the quasi-periodic structure is partially retained on the ridge surface (Fig. 1h). The oxygen content of the nearsurface layer changes from $20 \mathrm{wt} \%$ at the ridge periphery to $34 \mathrm{wt} \%$ in its central region. In this mode, the phase explosion starts from the first pulse.

SEM studies of the steel surface, which was affected by the fs-laser in high-fluence mode $4\left(F_{0} \approx 3.4 \mathrm{~J} / \mathrm{cm}^{2}\right.$ exceeds the $F_{\text {phe }}$ at $N=1$ by sixfold) for $N=600$, show uniform oxide layer (Fig. 2a, 2b), containing about $12 \mathrm{wt} \%$ oxygen. Because of poor adhesion, it is completely removed upon ultrasonic cleaning. Under this upper oxide layer, there is an underlying deeper oxide layer typical of the fs-laser-affected surface structure (Fig. 2c, 2d). The underlying oxide layer is seen in Fig. 2e to contain micropores.

Phase Composition of Near-Surface Layers. Fig. 3 shows the XRD patterns of steel surface. The steel surface obtained in mode $\mathbf{1}$ is seen (Fig. 3b) to consist of an austenitic $\gamma$-Fe ( $f c c)$ phase just as the nonirradiated sample (Fig. 3a) and $\alpha$-Fe (bcc) ferrite. The appearance of ferrite can be caused by local heating and hence by austenite $(\gamma) \rightarrow$ ferrite $(\alpha)$ partial phase transformation in fine near-surface layer. In the case of mode 2, peaks of austenite and magnetite (mixed oxide $\mathrm{Fe}_{3} \mathrm{O}_{4}$ ) are observed. Fig. $3 \mathrm{~d}$ shows that both ferrite and magnetite are present in the XRD pattern for surface modified in mode 3 . The equilibrium phase diagrams of Fe-Cr-Ni-C and Fe-O systems are shown in Fig. 4. 

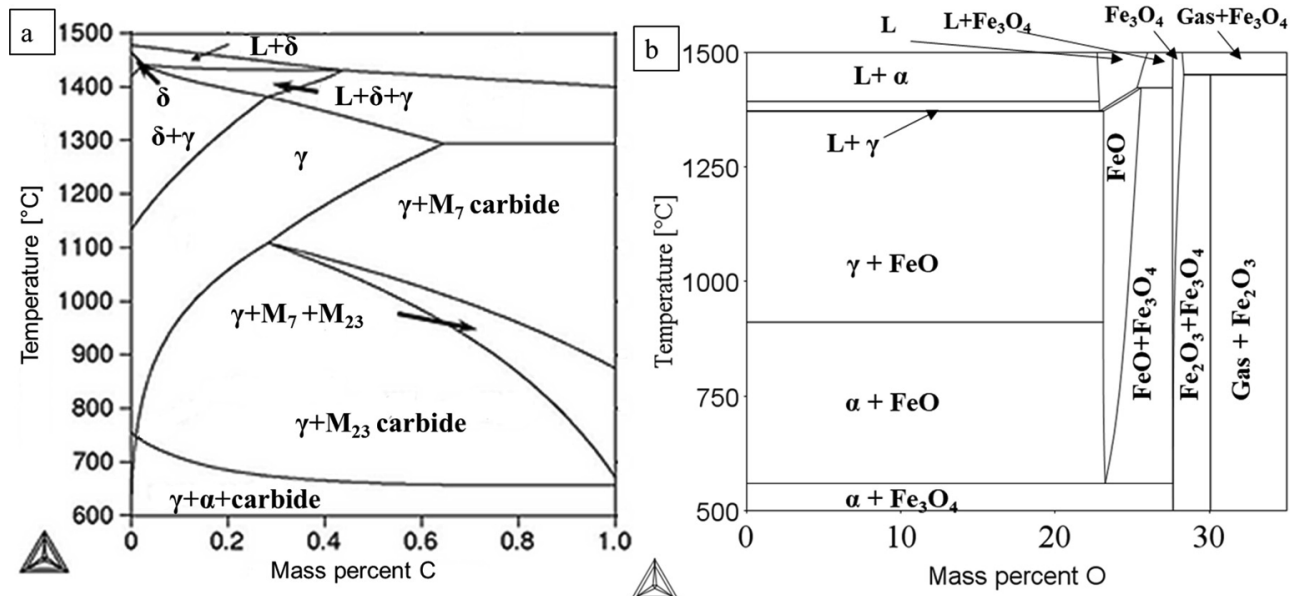

Fig. 4. Phase diagrams: a) austenitic stainless steel type 18-8 with carbon as a variable; b) Fe-O.

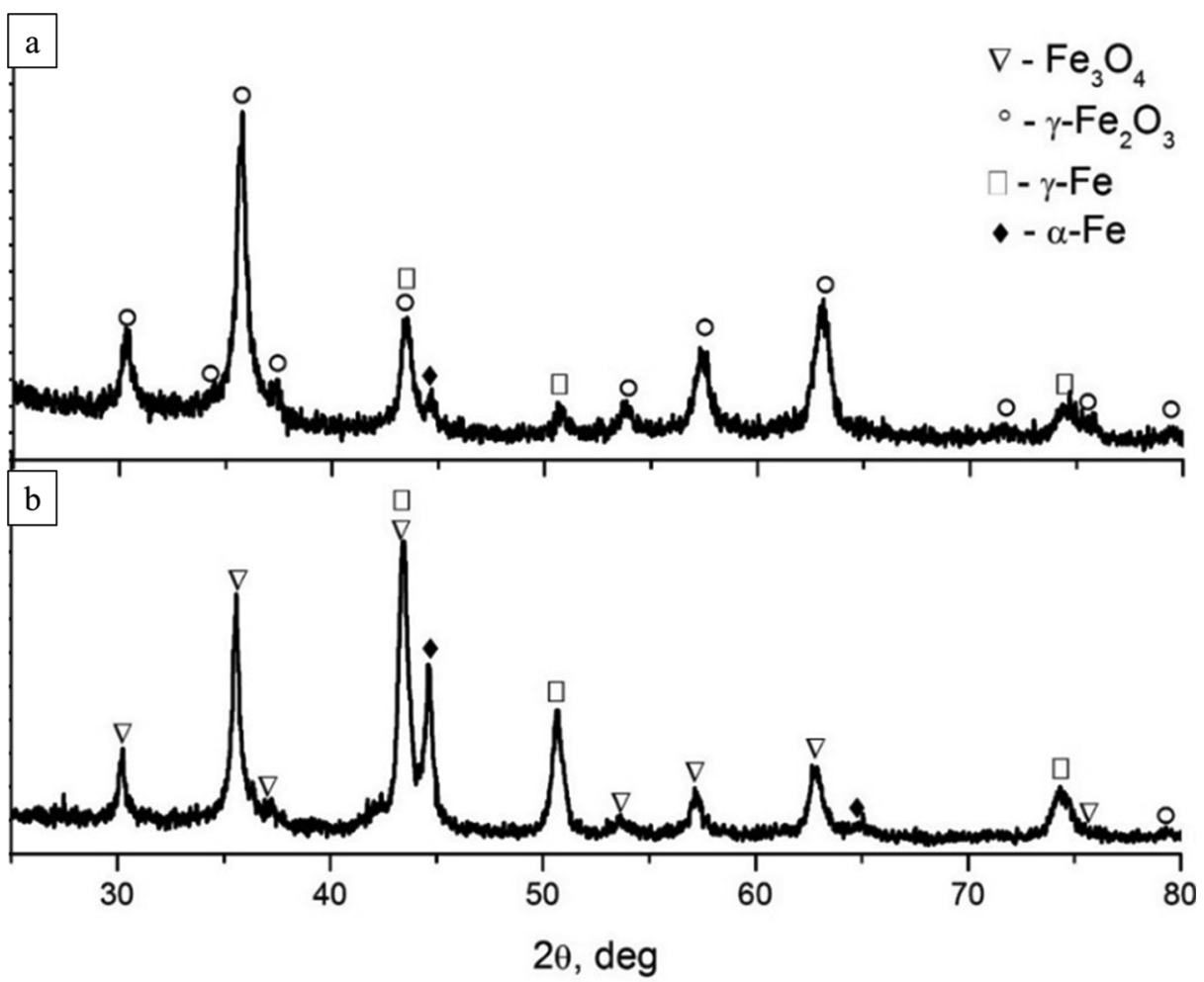

Fig. 5. XRD patterns of steel surface textured at $F_{0}=3.4 \mathrm{~J} / \mathrm{cm}^{2}$ and $N=600$ : (a) upper surface layer and (b) underlying deeper layer.

The XRD pattern of the steel surface irradiated in mode 4 is seen (Fig. 5a) to have peaks, belonging to $\gamma-\mathrm{Fe}_{2} \mathrm{O}_{3}$ (maghemite). However, since $\gamma-\mathrm{Fe}_{2} \mathrm{O}_{3}$ is isostructural to $\mathrm{Fe}_{3} \mathrm{O}_{4}$ (magnetite) [29], therefore, it is almost impossible to identify the $\mathrm{Fe}_{3} \mathrm{O}_{4}$ phase relative to $\gamma-\mathrm{Fe}_{2} \mathrm{O}_{3}$ by $\mathrm{XRD}$ analysis. Since the oxide upper layer is brown-red color, we assume that $\gamma-\mathrm{Fe}_{2} \mathrm{O}_{3}$ is its major phase; in addition, there are peaks of $\gamma$-Fe and $\alpha$-Fe. This upper layer was easily removed by ultrasonic cleaning. The underlying black-color oxide layer contains magnetite $\mathrm{Fe}_{3} \mathrm{O}_{4}$, austenite, and ferrite (Fig. 5b).

The oxides are seen (Fig. 6a, 6b) to grow normally to microridge surface, yielding columnar structures. In the case of mode 1 , no oxide layer is detected. The oxide layer thickness is about $300-500 \mathrm{~nm}$ for mode $\mathbf{2}$ and increases by one order of magnitude in case of mode $\mathbf{3}$
(Fig. 6a, 6b). As the oxide layer grows, its structure becomes microporous. The depth of microporous oxide layer formed in high-fluence mode 4 is up to $80 \mu \mathrm{m}$ (Fig. 6c-6e).

Structure of near-surface layers. In the initial state, the steel has a submicrocrystalline (SMC) structure with a mean grain size about $200 \mathrm{~nm}$ (Fig. 7a). The SMC structure remains unchanged under fs laser pulses at $F_{0} \approx 0.21 \mathrm{~J} / \mathrm{cm}^{2}$ and $F_{0} \approx 0.63 \mathrm{~J} / \mathrm{cm}^{2}$. Fig. $7 \mathrm{~b}$ and $7 \mathrm{c}$ show no heat-affected zone (HAZ).

The irradiation in mode 4 changes the near-surface layer structure. In the bulk of the microridges (see Fig. 8a) there are (a) equiaxial SMC grains; (b) columnar crystallites oriented normally to the lateral surface (see Fig. 8b); and (c) ultrafine grains of irregular shape (Fig. 8c). Nanoparticles are seen (Fig. $8 \mathrm{~d}$ ) to precipitate along the boundaries of 


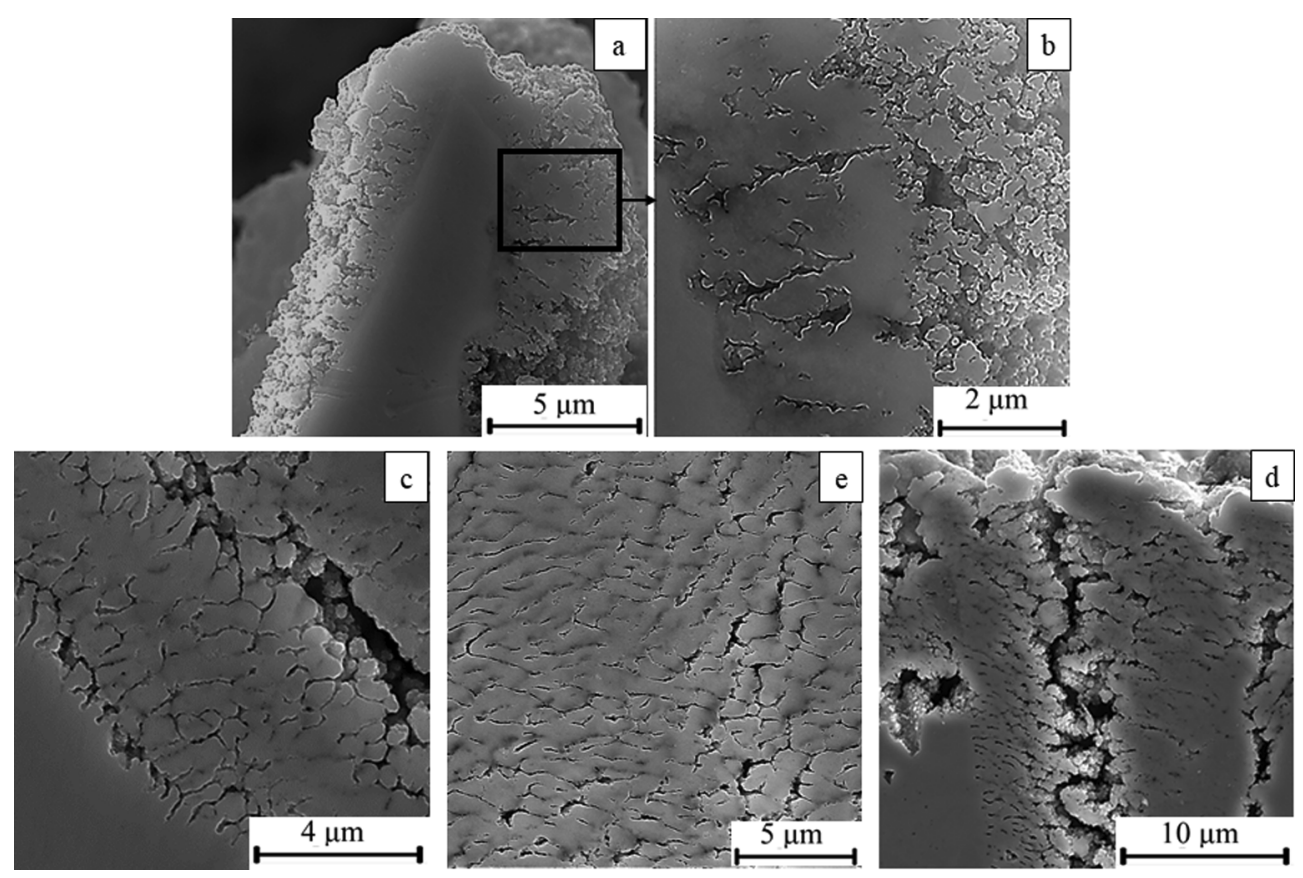

Fig. 6. Structure of cross section of steel samples affected by fs-laser pulses in (a, b) mode 3 and (c-e) mode 4.
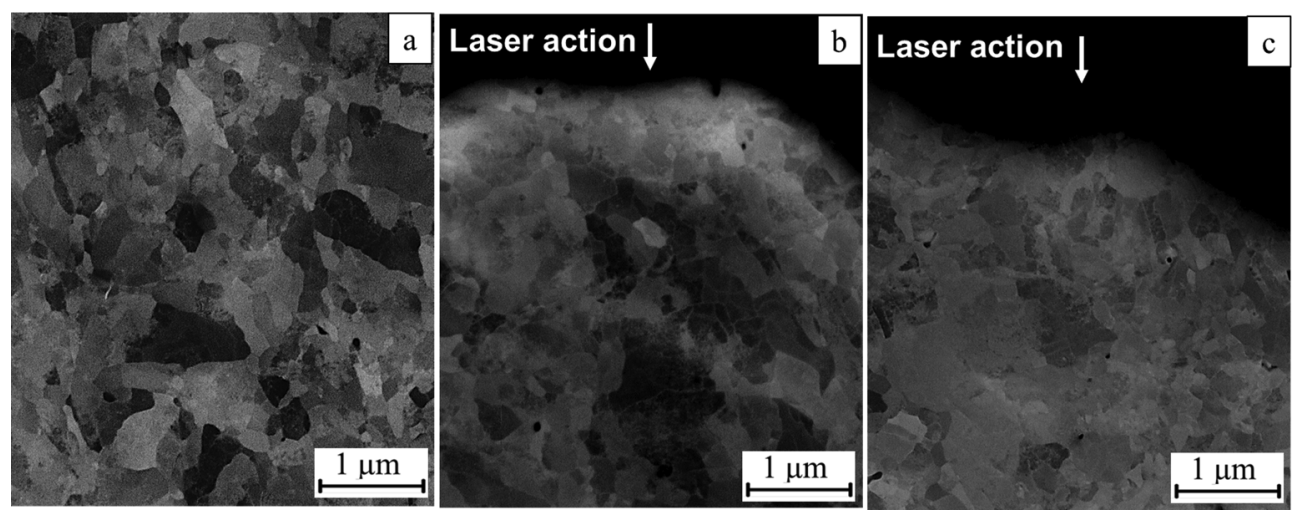

Fig. 7. Cross-sectional view of structure in near-surface layers (a) in the initial state and after fs laser radiation in (b) mode $\mathbf{2}$ and (c) mode $\mathbf{3}$.

elongated crystallites.

It is assumed that the depth of thermal diffusion into metallic materials is very small $(\sim 10-100 \mathrm{~nm})$ because of short pulse duration. So that the size of HAZ is also insignificant. Only a few experimental works have been focused on the process of HAZ formation but the fluence $(F)$ is high. HAZ was found to have a depth of $1.5-2 \mu \mathrm{m}$ in aluminum $[30,31]$ and $0.5-3.5 \mu \mathrm{m}$ in copper [32]. High-temperature copper-based alloy [33] showed no HAZ under the action of fs pulses at $F_{0}$ varying from 1 to 200 values of $F_{\text {th }}$ for this material. In our work, the HAZ appears in the near-surface layer of the AISI 321 steel irradiated in mode 4. Such a structure makes it possible to suggest the occurring of the processes of melting, ultrafast crystallization, and recrystallization.

\section{Conclusions}

Scanning-mode femtosecond laser irradiation of AISI 321 austenitic stainless steel surface in the spallation regime yields a nanograting decorated by nanoparticles with a $300-\mathrm{nm}$ period and submicrocrystalline (SMC) structure. In the phase explosion regimes, the SMC structure remains unchanged. In this case, the surface asperities (5 and $20 \mu \mathrm{m}$ high) covered with nano- and microporous oxide layers are formed. The phase explosion at higher fluences leads to formation of the microrelief of various roughness with different structural constituents in the bulk of the ridges: (a) equiaxial SMC grains; (b) columnar crystallites; and (c) ultrafine grains of irregular shape. In addition to upper oxide layer, containing $\gamma-\mathrm{Fe}_{2} \mathrm{O}_{3}$ as a basis with minor additions of $\gamma$-Fe and $\alpha$-Fe, the presence of an underlying layer of $80-\mu \mathrm{m}$ porous oxide $\left(\mathrm{Fe}_{3} \mathrm{O}_{4}\right.$ instead of $\left.\gamma-\mathrm{Fe}_{2} \mathrm{O}_{3}\right)$ is observed. The heat-affected zone is observed only in the near-surface layer of the AISI 321 steel irradiated in the high-fluence mode.

\section{CRediT authorship contribution statement}

M.V. Zhidkov: Conceptualization, Investigation, Writing - original draft. T.N. Vershinina: Data curation, Formal analysis, Writing - original draft. O.A. Golosova: Visualization, Writing - review \& editing. S.I. Kudryashov: Investigation, Writing - review \& editing. A.A. Ionin: Supervision. 


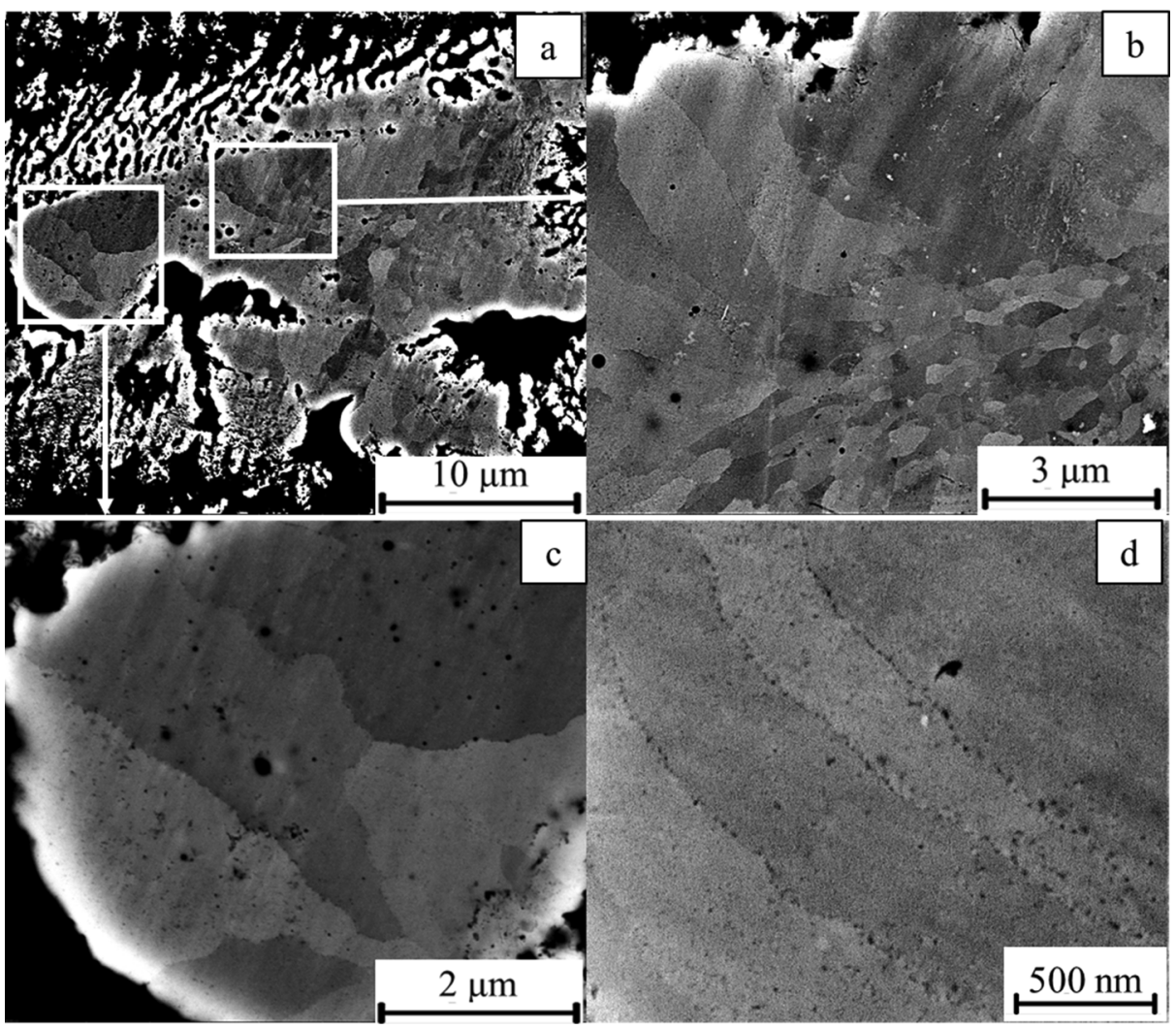

Fig. 8. Cross-sectional view of structure in near-surface layers after fs laser irradiation in mode 4.

\section{Declaration of Competing Interest}

The authors declare that they have no known competing financial interests or personal relationships that could have appeared to influence the work reported in this paper.

\section{References}

[1] L. Qi, K. Nishii, Y. Namba, Regular subwavelength surface structures induced by femtosecond laser pulses on stainless steel, Opt. Lett. 34 (2009) 1846-1848, https://doi.org/10.1364/OL.34.001846.

[2] J. Bonse, S. Höhm, A. Rosenfeld, J. Krüger, Sub-100-nm laser-induced periodic surface structures upon irradiation of titanium by Ti: sapphire femtosecond laser pulses in air, Appl. Phys. A. 110 (2013) 547-551, https://doi.org/10.1007/s00339012-7140-y.

[3] C.S.R. Nathala, A. Ajami, A.A. Ionin, S.I. Kudryashov, S.V. Makarov, T. Ganz, A. Assion, W. Husinsky, Experimental study of fs-laser induced sub-100-nm periodic surface structures on titanium, Opt. Express. 23 (2015) 5915-5929, https://doi. org/10.1364/OE.23.005915.

4] A.Y. Vorobyev, V.S. Makin, C. Guo, Periodic ordering of random surface nanostructures induced by femtosecond laser pulses on metals, 034903, J. Appl. Phys. 101 (2007), https://doi.org/10.1063/1.2432288.

[5] C. Albu, A. Dinescu, M. Filipescu, M. Ulmeanu, M. Zamfirescu, Periodical structures induced by femtosecond laser on metals in air and liquid environments, Appl. Surf. Sci. 278 (2013) 347-351, https://doi.org/10.1016/j.apsusc.2012.11.075.

[6] A.A. Ionin, S.I. Kudryashov, S.V. Makarov, A.A. Rudenko, L.V. Seleznev, D.V. Sinitsyn, E.V. Golosov, Yu.R. Kolobov, A.E. Ligachev, Beam spatial profile effect on femtosecond laser surface structuring of titanium in scanning regime, Appl. Surf. Sci. 284 (2013) 634-637, https://doi.org/10.1016/j.apsusc.2013.07. 144.

[7] Yu.R. Kolobov, M.Yu. Smolyakova, A.Yu. Kolobova, A.A. Ionin, S.I. Kudryashov, S.V. Makarov, P.N. Saltuganov, D.A. Zayarny, A.E. Ligachev, Superhydrophylic textures fabricated by femtosecond laser pulses on sub-micro- and nano-crystalline titanium surfaces, 125602, Laser Phys. Lett. 11 (2014), https://doi.org/10.1088/ $1612-2011 / 11 / 12 / 125602$.

[8] A.M. Kietzig, S.G. Hatzikiriakos, P. Englezos, Patterned superhydrophobic metallic surfaces, Langmuir 25 (2009) 4821-4827, https://doi.org/10.1021/la8037582.

[9] D.H. Kam, S. Bhattacharya, J. Mazumder, Control of the wetting properties of an AISI 316L stainless steel surface by femtosecond laser-induced surface modification, 105019, J. Micromech. Microeng. 22 (2012), https://doi.org/10.1088/0960-1317/ 22/10/105019.

[10] A.Y. Vorobyev, C. Guo, Multifunctional surfaces produced by femtosecond laser pulses, 033103, J. Appl. Phys. 117 (2015), https://doi.org/10.1063/1.4905616.

[11] J.E. Carey, C.H. Crouch, M. Shen, E. Mazur, Visible and near-infrared responsivity of femtosecond-laser microstructured silicon photodiodes, Opt. Lett. 30 (2005) 1773-1775, https://doi.org/10.1364/OL.30.001773.

[12] A.Y. Vorobyev, V.S. Makin, C. Guo, Brighter light sources from black metal: significant increase in emission efficiency of incandescent light sources, 234301, Phys. Rev. Lett. 102 (2009), https://doi.org/10.1103/PhysRevLett.102.234301.

[13] B. Wu, M. Zhou, J. Li, X. Ye, G. Li, L. Cai, Superhydrophobic surfaces fabricated by microstructuring of stainless steel using a femtosecond laser, Appl. Surf. Sci. 256 (2009) 61-66, https://doi.org/10.1016/j.apsusc.2009.07.061.

[14] B.K. Nayak, M.C. Gupta, Self-organized micro/nano structures in metal surfaces by ultrafast laser irradiation, Opt. Lasers Eng. 48 (2010) 940-949, https://doi.org/10. 1016/j.optlaseng.2010.04.010.

[15] V.V. Iyengar, B.K. Nayak, M.C. Gupta, Ultralow reflectance metal surfaces by ultrafast laser texturing, Appl. Opt. 49 (2010) 5983-5988, https://doi.org/10.1364/ AO 49.005983.

[16] S. Moradi, S. Kamal, P. Englezos, S.G. Hatzikiriakos, Femtosecond laser irradiation of metallic surfaces: effects of laser parameters on superhydrophobicity, 415302, Nanotech. 24 (2013), https://doi.org/10.1088/0957-4484/24/41/415302.

[17] C.Y. Lin, C.W. Cheng, K.L. Ou, Micro/nano-structuring of medical stainless steel using femtosecond laser pulses, Phys. Procedia 39 (2012) 661-668, https://doi.org/ 10.1016/j.phpro.2012.10.086.

[18] R. Jagdheesh, B. Pathiraj, E. Karatay, G.R.B.E. Romer, A.J. Huis in't Veld, Laserinduced nanoscale superhydrophobic structures on metal surfaces, Langmuir 27 (2011) 8464-8469, https://doi.org/10.1021/la2011088.

[19] N. Saltuganov, A.A. Ionin, S.I. Kudryashov, A.A. Rukhadze, I. Gavrilov, S.V. Makarov, A.A. Rudenko, D.A. Zayarny, Fabrication of superhydrophobic coating on stainless steel surface by femtosecond laser texturing and chemisorption of an hydrophobic agent, J. Rus. Laser Res. 36 (2015) 81-85, https://doi.org/10. 1007/s10946-015-9480-5.

[20] M. Martínez-Calderon, A. Rodríguez, A. Dias-Ponte, M.C. Morant-Miñana, M. Gómez-Aranzadi, S.M. Olaizola, Femtosecond laser fabrication of highly hydrophobic stainless steel surface with hierarchical structures fabricated by combining ordered microstructures and LIPSS, Appl. Surf. Sci. 374 (2016) 81-89, https://doi.org/10.1016/j.apsusc.2015.09.261.

[21] J.S. Hoppius, L.M. Kikreja, M. Knyazeva, F. Pöhl, F. Walther, A. Ostendorf, E.L. Gurevich, On femtosecond laser shock peening of stainless steel AISI 316, Appl Surf. Sci. 435 (2018) 1120-1124, https://doi.org/10.1016/j.apsusc.2017.11.145.

[22] H. Nakano, S. Miyauti, N. Butani, T. Shibayanagi, M. Tsukamoto, N. Abe, Femtosecond laser peening of stainless steel, J. Laser Micro/Nanoeng. 4 (2009) 35-38, https://doi.org/10.2961/jlmn.2009.01.0007.

[23] I.A. Artyukov, D.A. Zayarniy, A.A. Ionin, S.I. Kudryashov, S.V. Makarov, P.N. Saltuganov, Relaxation phenomena in electronic and lattice subsystems on iron surface during its ablation by ultrashort laser pulses, JETF Lett. 99 (2014) 51-55, 
https://doi.org/10.1134/S0021364014010020.

[24] A.A. Ionin, S.I. Kudryashov, A.A. Samokhin, Material surface ablation produced by ultrashort laser pulses, Phys. Usp. 60 (2017) 149-160, https://doi.org/10.3367/ UFNr.2016.09.037974.

[25] Y. Jee, M.F. Becker, R.M. Walser, Laser-induced damage on single-crystal metal surfaces, J. Opt. Soc. Am. B. 5 (1988) 648-659, https://doi.org/10.1364/JOSAB.5. 000648.

[26] G. Raciukaitis, M. Brikas, P. Gecys, M. Gedvilas, Accumulation effects in laser ablation of metals with high-repetition rate lasers, Proc. SPIE. 7005 (2008) 70052L, https://doi.org/10.1117/12.782937.

[27] P.T. Mannion, J. Magee, E. Coyne, G.M. O'Connor, T.J. Glynn, The effect of damage accumulation behavior on ablation thresholds and damage morphology in ultrafast laser micro-machining of common metals in air, Appl. Surf. Sci. 233 (2004) 275-287.

[28] A. Abou-Saleh, E.T. Karim, C. Maurice, S. Reynaud, F. Pigeon, F. Garrelie, L.V. Zhigilei, J.P. Colombier, Spallation-induced roughness promoting high spatial frequency nanostructure formation on Cr, Appl. Phys. A. 124 (2018) 308, https:// doi.org/10.1007/s00339-018-1716-0.
[29] M.A. Morales, P.V. Finotelli, J.A.H. Coaquira, M.H.M. Rocha-Leão, C. Diaz-Aguila, E.M. Baggio-Saitovitch, A.M. Rossi, In situ synthesis and magnetic studies of iron oxide nanoparticles in calcium-alginate matrix for biomedical applications, Mater. Sci. Eng. C 28 (2008) 253-257, https://doi.org/10.1016/j.msec.2006.12.016.

[30] R. Le Harzic, N. Huot, E. Audouard, C. Jonin, P. Laporte, Comparison of heat-affected zones due to nanosecond and femtosecond laser pulses using transmission electronic microscopy, Appl. Phys. Lett. 80 (2002) 3886-3888, https://doi.org/10. 1063/1.1481195.

[31] S. Valette, E. Audouard, R. Le Harzic, N. Huot, P. Laporte, R. Fortunier, Heat affected zone in aluminum single crystals submitted to femtosecond laser irradiations, Appl. Surf. Sci. 239 (2005) 381-386, https://doi.org/10.1016/j.apsusc.2004.06. 003

[32] Y. Hirayama, M. Obara, Heat-affected zone and ablation rate of copper ablated with femtosecond laser, 064903, J. Appl. Phys. 97 (2005), https://doi.org/10.1063/1 1852692.

[33] Q. Feng, Y.N. Picard, H. Liu, S.M. Yalisove, G. Mourou, T.M. Pollock, Femtosecond laser micromachining of a single-crystal superalloy, Scr. Mater. 53 (2005) 511-516, https://doi.org/10.1016/j.scriptamat.2005.05.006. 